\section{FUNGI AND MODERN AFFAIRS*}

\author{
By DR. J. RAMSBOTTOM, O.B.E. \\ British Museum (Natural History)
}

$I^{\mathrm{T}}$ $T$ is a little surprising that fungi should have received so little consideration from academic botanists, for they are more numerous in species and in individuals than is the rest of the plant kingdom. They are classed in the vegetable kingdom, for with the old divisions, plants, animals and minerals, there is nowhere else for them. But they are not plants in the ordinary sense of the word as they have no chlorophyll and there is no evidence that they were derived from organisms so provided. A great amount of research has been carried out during the last halfcentury to ascertain the precise methods by which green plants build up carbohydrates; but compara. tively little attention has been paid to the manifold and diverse physiological processes by which fungi obtain their nutriment. In their search for food, fungi play many parts in the drama of Nature and in modern affairs.

To many the word fungus conveys the idea of something mysterious or foreboding: to others mushrooms and toadstools. J. Bauhin appeared to combine the two ideas when he derived the word from funus (funeral) and ago (to put in motion), a derivation which John Ray considered appropriate even if possibly not correct.

What is a mushroom? The term is often loosely applied to those larger fungi which are edible, it being assumed that only the field mushroom and possibly one or more of its near allies are safe to eat ; the rest, assumed to be poisonous, are grouped together as toadstools. But the assumption puts the facts the wrong way round, for there are less than a dozen species which are in any way poisonous; the vast majority are harmless. It would be illogical to speak of even the three hundred or more edible species as mushrooms and the others as toadstools; it seems preferable to call all agarics 'toadstools', restricting 'mushroom' for the species of the genus Psalliota : in this way, moreover, some of our insular and peculiar prejudice against them might be toned down.

Toadstools have been eaten from the earliest times. There is no reference to them in the Bible, but classical writers leave us in no doubt that fungi were well known as peculiar organisms of strange growth, so well known indeed that they were the subject of puns. Accidents sometimes occurred and, as these seem to be specially noted, it has been assumed by some that the use of fungi as food was regarded as too dangerous to be indulged in. What is more probable was that fungi were a common food, but accidents were especially noted because of the difficulty of distinguishing between wholesome and poisonous species. It was comparatively simple to get a knowledge of what plants and fruits are safe to eat for they are easy to recognize again, they are lasting, and, even if annual, they are constant in their time and place. Consequently they all had names. Fungi, on the other hand, are difficult to describe, and the fleshy ones are of irregular occurrence and of short duration. For this reason we find rules for distinguishing between edible and poisonous species rather than names and descriptions. Many of these rules are still current--'peeling', and the non-blackening

* Substance of three lectures at the Royal Institution, delivered on February 15, 22 and 29. of a silver spoon being the most widely believed, and this throughout Europe, possibly owing to them being repeated in the old herbals. All are utterly worthless, even dangerous. There is only one real test. Many have tried it, and as there are numerous records of experiments which ended in disaster, we have a mass of evidence which relieves us of the necessity of personal trial.

It is only in Great Britain that toadstools are rejected as food. Eighty years ago, five or six species were on sale in Covent Garden Market; but later only the mushroom, wild or cultivated, was displayed. It is hard to account for the British prejudice against them. It has been suggested that it is because of our high standard of living, or alternatively because of the absence of well-wooded country: but these do not explain the fear most people have of them.

In Continental countries with hard and long winters, fungi are dried and pickled and form a staple food while the frosts last; they also serve in place of meat during religious fasts. In all Continental countries fungi are sold in the markets, and many towns have special fungus markets. Usually there is some sort of control, and the number of species allowed to be sold varies from half a dozen to more than three hundred.

Though in Great Britain the chief use of toadstools is as appetizing additions to other dishes, they have a certain food value: There is need of more precise information on this, for many of the old analyses led to extravagant claims. Darwin recorded that the Terra del Fuegians eat no vegetable food except Cyttaria and a few berries, whereas Lettow-Vorbeck recounts that when, during the East African campaign of the War of 1914-18 the difficulties with food had reached a most embarrassing stage, the German troops were able to carry on owing to finding enormous quantities of edible fungi which were to them as manna was to the children of Israel.

There are a number of species which have always had a good reputation as edible, which moreover are easy to identify and which cannot readily be confused with any poisonous forms. For those not making a special study of the subject, it is advisable to learm to recognize some of these, rather than to experiment with others about which all that is known is that they are not among those regarded as poisonous.

The most deadly poisonous species is Amanita phalloides (including the two white varieties or closely allied species $A$. verna and $A$. virosa). It is responsible for practically all the recorded deaths from fungus poisoning and the death-rate is more than 50 per cent -indeed, it has been put as high as 90 per cent. There is a characteristic period of quiescence after the fungus is eaten, on an average twelve hours, though it may be as long as forty. Death may occur on the first day, but is usually on the third or fourth day. There are apparently four poisons contained in this species: Amanita hæmolysin (phallin), a glucoside readily destroyed by heat and digestive juices ; Amanita toxin with a complicated and indefinite chemical structure; and according to the work of F. Lynen and U. Wieland (1937), phalloidin, which is quickly acting though destroyed by heat, and an additional slower-acting toxin. Death through eating the cooked fungus is apparently due to the heatresistant Amanita toxin. Cures have been reported by the use of a 'sérum antiphalloidien' prepared at the Pasteur Institute; by intravenous injection with 20 per cent glueose solution; by intravenous injection with 10 per cent sodium chloride solution; by 
administering the finely chopped up stomachs of three rabbits and the brains of seven.

Amanita mappa, formerly considered as very poisonous, is edible but not worth eating. Amanita muscaria, which contains muscarin, mycotoatropin and choline, does not cause death in healthy people. The symptoms of poisoning usually simulate alcoholic intoxication, though there are occasionally gastrointestinal disturbances. Amanita pantherina produces similar symptoms.

The remaining species which are in any way dangerous, raw or cooked, are Lepiota helveola, Entoloma lividum, Inocybe Patouillardi, Boletus Satanas and Gyromitra esculenta, though some other species are very indigestible and consequently may cause disturbance.

Claviceps purpurea (ergot) is a poisonous fungus of another group. The two different types of ergotism, the convulsive and the gangrenous, are now well known. Five alkaloids have been isolated from ergot : ergotinine, ergotoxine, ergotamine, ergotaminine and ergometrine. As its name suggests, ergosterol was first extracted from ergot; histamine also. The use of ergot in childbirth is mentioned by Lonicer in 1582 in the first record of the fungus. At present ergot is the only fungus which figures in the British Pharmacopœia.

Fungi, being without chlorophyll, have a physiology which in many ways is more animal-like than plantlike. Obviously there are two main sources of food, living organisms and dead organic material. Fungi make use of both-they parasitize all kinds of living organisms, and there is no sort of organic matter not liable to attack. But though they are responsible for the greater part of plant diseases and they cause destruction to stored products of every kind, the changes they bring about are not all to our detriment as living organisms. They act as scavengers reducing dead material into substances available for plant life, and moreover prevent the cluttering up of the earth's surface. The action of soil fungi on plant material was overlooked when untreated jute sandbags were filled with sand and even ordinary earth at the outbreak of the present War. The modern compost heap is a contrivance to bring about the breaking down of similar cellulose sub. stances.

Forest trees are subject to attack by larger fungi as well as by microscopic forms. Timber from such trees is unsuitable for most purposes and, moreover, if not properly seasoned, may continue to rot. Fallen logs and stumps have a characteristic flora, and soveral of the species occur on wooden fences, gateposts and similar structures; Lentinus lepideus, for example, attacks wood pavement blocks, telegraph poles and railway sleepers.

If wood is to be preserved, it must be kept dry or treated with some fungicide. The chief agent of destruction of structural timber is Merulius lacrymans, the dry-rot fungus: there are other fungi causing dry rot, but the damage they produce is trivial. If timber is properly seasoned and then kept dry by ventilation so that it never contains as much as 20 per cent moisture, the fungus will not attack it ; otherwise damage is almost certain. At the present time, the amount of dry rot in London calls for serious attention. It is easy to understand how houses which have been severely bombed are liable to have their timber affected, but blast has cracked waterpipes with a consequent seepage of water through the walls; leaves and other rubbish have caused overflows which run down the walls; shelters have been constructed so that ventilation and even watercourses have been interfered with; ventilation bricks have been stopped up to prevent entrance of gas; or sand-bags which became rain-sodden propped up against walls, often over air-bricks; houses left unattended, with no heat and leaky roofs; water-tanks and pipes bursting, water-taps left running in requisitioned buildings all have played their part in bringing about a good deal of unnecessary waste. Furthermore, there is need for some scientific control over new housing plans or we shall have a repetition of the troubles which affected whole building estates after the War of 1914-18.

In addition to causing diseases of trees, microscopic fungi cause disease not only of crops but also of wild plants. The most striking point about the flora of bombed sites is the rapid appearance of special fungus parasites, as for example Bremia Lactucce on groundsel. The idea that disease is a result of civilization is very attractive to some minds -but is entirely false.

Fungi are the main causal agents of disease in plants. The losses in different erops vary normally from 2 to 50 per cent : figures for the U.S.A. for wheat, oats and barley in 1935 due to rust alone were estimated at 277, 185 and 53 million bushels respectively. There are many ways of combating fungus attacks, the most obvious being the use of fungicides. Much depends upon having a thorough knowledge of the life-history of the parasite as well as that of the host plant, for then the fungus can be tackled at its most vulnerable stage.

Some varieties or races of plants are immune to the strain of fungus parasite common in the neigh. bourhood, and much work has been done in the attempt to breed immune races. But it is frequently overlooked that there is often as much variation in the parasite as in the host. Thus the problem of producing a wheat immune to black stem rust theoretically necessitates the building up of a resistance to 177 physiological races, though, practically, only the local strains present in any one area need be considered.

Less than a century ago, when the parasitic nature of many diseases was beginning to be suspected, fungi were thought to be responsible for many human affections. This was a consequence of Schoenlein's discovery in 1839 of the fungus causing favus, which was immediately followed by Lagenbeck's describing the fungus of thrush, and soon afterwards by Gruby's description of ringworm. With the gradual recognition of the predominance of bacterial diseases and the abundant problems they presented, mycology, except for the obvious dermatophytosis and actinomycosis, has not received the attention due to it, especially in Great Britain. Many of the ring-worm group are able to live parasitically on domestic animals; some are known to live saprophytically on organic debris and others have been reported as capable of infecting living plants. Athletes' toe (Trichophyton spp., Epidermophyton) has become increasingly common in Great Britain during the past few years and is prevalent in certain sections of the Fighting Services. But there are many less obvious diseases which have been studied principally in France and America. That they exist elsewhere is shown by the recent recognition of histoplasmosis (Histoplasma capsulatum) in Great Britain. The symptoms of this disease are protean; they may simulate kala azar or pulmonary tuberculosis-and 
the prognosis is bad. A recent discovery by C. W. Emmons that small desert rodents constitute an important natural reservoir of Coccidioides immitis, the cause of coccidioidal granuloma, is of importance. This disease has been known for about half a century in North and South America and was thought to be soil-borne. The Medical Research Council has recently appointed a committee to report on the situation of medical mycology in Great Britain.

Animals other than those domesticated are also liable to fungal disease. Insects particularly are affected, whole groups of fungi being entomogenous ; as, for example, the Laboulbeniales with about 120 genera and 1,500 species, so well monographed by Thaxter. Moreover, it has been shown recently by C. Dreschler that there are a number of species, Entomophthoraceæ and Hyphomycetes, which parasitize nematodes, amobre and other small soil inhabitants.

The extent of the darnage by fungi to stored products of all kinds is only gradually being realized. The losses in textiles have received most attention and the investigations of the conditions in which cotton and wool become 'mildewed' are influeneing the practices of manufacture. The methods of preserving foodstuffs - sterilization, canning, pickling and so on-are chiefly to prevent mould attack, though they also protect them from bacterial contamination.

The outward and visible sign of specific differences in fungi is morphological as in green plants and animals, but this should not mask the fact that a given species growing under definite conditions always acts in the same way and brings about the same results. Can we so harness any species that it will produce results useful to us? What has Nature herself done in this direction?

Armillaria mellea is a common toadstool which causes a good deal of disease in trees but is also able to live saprophytically. It spreads by means of rhizomorphs, strands of compacted mycelium which look somewhat like flattened, branched and anastomosing, black leather bootlaces. If these encounter potato tubers, they reduce them to mush in two or three days. On the other hand, if the rhizomorphs meet the tubers of the Japanese saprophytic orchid Gastrodia elata, they penetrate for only a certain distance and are then held in check. An uninfected tuber sends out a dropper and the process is repeated each year until a tuber is formed which is too small to grow. An infected tuber, however, sends out a dropper which produces an inflorescence the following year. It is obvious that the orchid obtains nutriment from the rhizomorphs, which presumably act as conducting strands. It may be that in some such reversal of parasitism we have a clue to the origin of the more typical mycorrhiza or fungus-root. Orchids are the classical example of obligate sym. biosis, the seeds not normally germinating unless infected by the fungus present in certain cells of the roots. In modern methods of commercial orchid growing, either the seeds are infected artificially with the appropriate fungus, or its action is replaced by sowing sterilized seeds on a medium containing sugar.

Forest trees have a layer of fungal hyphæ surrounding many of the absorbing rootlets, the fungi concerned being mainly of the toadstool type. Many perennial plants also have mycorrhizas, but it is not yet certain which fungi are concerned: the usual appearance is suggestive of Phycomycetes. Similar associations with fungi occur throughout the plant kingdom.

The association of fungus and alga has resulted in the large homogeneous class Lichens.

Many insects have internal yeasts : indeed, these are supposed to have played a definite part in the evolution of some insect groups. A more obvious harnessing is that of the leaf-cutting ants of South America which, as first described by Bates and amply confirmed since, cultivate fungi of the toadstool type in their fungus gardens. An association in which the fungus seems to be less in subjection is that of bacteria and yeast which are active in various fermented drinks-Mexican tibi, koumiss, kephir, leben, tea cider, ginger-beer plant-some fermenting sugary liquids, others milk.

In addition to these combined masses, which are usually in the form of grains, man in his early history noted that fruit juices or other sugary fluids underwent a change if left for some time: honey-comb washings became mead, grape juice became wine. These much appreciated changes, the work of yeasts, were not to be left to blind chance, and in the course of centuries the conditions controlling the changes and finally the reason for them became known. Nowadays distillers, brewers, many wine growers and cider manufacturers no longer rely on some general supply or on casual wild yeasts, but maintain pure cultures of special strains of the appropriate species which have proved to give the best results in the conditions of production. Here we have the breaking down of organic matter by fungi to give a desired result. It must be stressed, however, that a fungus acts only in a certain way in definite circumstances.

Pasteur's classical researches on fermentation were a direct outcome of the misfortunes that befell France after the war of 1870. It is surprising how often an odd fact he mentioned more or less incidentally has been followed up by later investigations. Thus during the War of 1914-18, German scientific men turned their attention to Pasteur's observations that proteins could be synthesized by yeasts from inorganic nitrogen, including ammonium salts. The fact that yeast, including brewers' yeast, contains a high percentage of protein had long been known and attempts were made to utilize the surplus quantities from brewers until the production of beer was cut by 60 per cent. In 1915, Hayduck announced that he had discovered what he called 'mineral yeast', as a contaminant at a pressed yeast factory. This yeast, which is non-sporing and was afterwards called Tomula utilis, gave much better yields of protein than did other yeasts and, moreover, produced little alcohol. A yeast product was put on the market, but large-scale production apparently could not be carried on because of lack of sugar.

With the outbreak of the present War, the possibility of a shortage of protein had to be faced, and the problem was allotted to $\mathbf{A}$. C. Thaysen and his colleagues at the Chemical Research Laboratory. Eventually they decided that Torula (Torulopsis) utilis was most likely to prove satisfactory. As the situation developed, it was realized that the post-war feeding of ravaged Europe would be one of the major problems, and that for some time vitamin $B$ deficiency would be an additional danger. An analysis of dried Torula utilis showed that as well as $45-50$ per cent of a protein only slightly less nutritive than a good animal protein, this 'food yeast' contains the whole known range of water-soluble $B$ vitamins. Further, 
it mixes readily with water and with milk and can be used in all sorts of ways. Large-scale manufacture is to be carried out in Jamaica where molasses is abundant $-200 \mathrm{gm}$. of molasses give $50-60 \mathrm{gm}$. of food yeast. The Colonial Development Fund has granted $£ 150,000$ for the erection of the plant and it is estimated that 'food yeast' can be marketed at $6 d$. per lb. Many other parts of the Empire are considering erecting plants for the benefit of the local population. It is understood that in Germany the yeast is again being used with hydrolysed wood as the source of sugar.

At Teddington, a strain of T. utilis was developed which will grow better at tropical temperatures than would the normal form. It gives a quicker yield and has less variability in size. Later, a giant strain (v. major) was produced by acting on the cells with camphor: the biochemical activities are identical, the variety is stable, its cells are more readily separable and its generative time is considerably less.

Another observation by Pasteur was that in ordinary yeast fermentation a small percentage of glycerine is always produced. During the War of 1914-18, the Germans were short of glycerol for making explosives. Neuberg, in 1911, had begun to publish his studies on the stages leading to alcohol formation by yeasts. When experimenting on aldehyde fixation with sodium sulphite, there was a large increase in the percentage of glycerol. Connstein and Lüdecke successfully applied this to largescale production : many will remember the wild guesses that were made at the time concerning the source of the enemy's glycerine. They produced 1,000 tons a month by the method, the average yield being 20-25 per cent of the sugar used, and in addition large quantities of alcohol and acetaldehyde were obtained as by-products. It has been said that it enabled the Germans to carry on the war for another twelve months. The Americans, hearing that glycerine was being produced by yeasts, succeeded in devising a couple of similar processes. H. Raistrick and his colleagues, after 1918, used a modified sulphite process at Nobel's factory at Ardeer and increased the yields of glycerine in the fermentation liquor to 35-40 per cent of the weight of sugar fermented. Subsequent improvements in the methods of recovery of glycerine from the fermentation liquors have reduced the cost of fermentation glycerine to a figure comparable with that of soap lye glycerine.

One of Pasteur's statements, "We are convinced that a day will come when moulds will be utilised in certain industrial operations, on account of their power of destroying organic matter"*, in spite of its definiteness, was generally disregarded. However, his favourite pupil van Tieghem established the importance of moulds in the biochemical field. $\mathrm{He}$ investigated the method of production of gallic acid from heaps of vegetable matter containing tanningall nuts, sumach, tea, etc-watered and allowed to go mouldy. He showed in 1867 that the mould principally concerned is Aspergillus niger. The present-day method of production is to inoculate clear tannin extract with this fungus.

It was not until 1893 that the first real advance was made, when Wehmer described the production of citric acid by two species of Penicillium (Citromyces) grown in nutrient sucrose solutions containing calcium carbonate. It has been found that a number

\footnotetext{
" "Studies on Fermentation". By L. Pasteur. English translation 1879, p. 261 . I am indebted to Dr. J. Yuill for directing my attention to this.
}

of moulds produce citric acid, but the one used on a commercial scale is Aspergillus niger. In 1922, Italy produced about 90 per cent of the world's supply of calcium citrate from citrous juices, but within eight years the export had practically stopped because of the commercial production by moulds $-10,000,000 \mathrm{lb}$. annually in the U.S.A. alone. There is now an International Citric Acid Agreement.

The process is a surface fermentation of a nutrient sucrose solution, with a comparatively large amount of mineral acid which prevents the growth of bacteria and most moulds. The solution is seeded with spores of Aspergillus niger, and as these germinate the surface becomes covered with a frail pellicle which rapidly develops and, by the end of the fermentation (8-12 days), becomes a fairly thick and deeply intricately folded mat but still quite white. Most of the sugar has by then disappeared from the solution, its place being taken by eitric acid practically unaccompanied by other organic acids : the solution is much more acid than good lemon juice. Some of the sugar, however, is converted into fungus starch and some into dextrin. The standard way to recover the citrie acid from the fermented liquor is to add milk of lime and heat nearly to boiling point, then filter off the difficultly soluble calcium citrate and wash with hot water.

Another process in which Aspergillus niger is used is the production of gluconic acid, the calcium salt of which is of importance in pharmacy. Here the best results are obtained from well-aerated submerged growth, which is most economically accomplished by using rotatory drums.

Moulds are able to build up their normal cell constituents from an amazingly large and varied series of carbon compounds. Moreover, as seen with Aspergillus niger, the same species of mould, when growing in slightly different conditions, can produce different substances. Citric acid, oxalic acid, gluconic acid, ethyl alcohol and mannitol, which may be regarded as the breakdown products of the original sugars, are formed by many species.

There are, however, many substances which are built up by mould growth, and for the most part these are highly specific products of a single species, or of a few related species. The chief worker in this field has been Raistrick, who, following on his work on glycerol production, has been engaged with numerous collaborators in investigating the general biochemistry of moulds. The scheme followed has been to use glucose as the sole source of carbon in a synthetic culture medium-usually Czapek-Dox medium. In this long-continued and productive research, about a hundred substances previously unknown to science have been prepared and many of them synthesized. It may well be that some of these will be found useful in some way or other, but their present interest is chiefly in giving us a picture of what happens inside the cell. Mould pigments, simple quinones, polyhydroxy-anthraquinones and hydroxyxanthones, simple benzene compounds, chlorine-containing metabolic products, derivatives of tetronic acid (stimulants of bacterial growth), antibacterial and antifungal substances are included in the products*. It is a mattier of phylogenetic interest that the lichen acid physcion (parietin) is formed by sixteen species or strains in the Aspergillus glaucus series.

To understand the magnitude of work of this kind one has to take into consideration that in a given

* A wide range of these special chemical compounds was exhibited. 
species there are strains some of which are more active, some less; further, that the results differ according to the chemical constitution of the medium and the physical conditions of growth.

Ever since fungi and bacteria were grown on artificial media, it has been observed that in mixed cultures one organism may have no apparent effect on the growth of the other, or it may influence it either favourably or unfavourably. This favourable effect (synergism) may be considered as an aspect of symbiosis; the unfavourable (antagonism) as an aspect of the struggle for existence.

Antagonism is gradually becoming recognized as a factor in plant disease. The fungi which abound in the soil include some species which are able to become parasites and cause destructive root rots. Chemical and physical conditions of the soil determine the amount of a given species, but they also act on the other fungi present, one or more of which may have an antagonistic reaction towards the parasite. Thus the mould Trichoderma viride, common in the soil, has an antagonistic effect on the growth of the tree parasite Armillaria mellea.

The phenomenon of antagonism has been brought strikingly to public notice following an observation by $A$. Fleming in 1928. When studying the growth of Staphylococcus on solid media in Petri dishes, he noticed that the colonies underwent lysis in a zone surrounding a growth of Penicillium which contaminated one of his cultures. He grew the Penicillium in broth culture, and found that the filtrate was some two or three times as effective as pure carbolic acid in stopping the growth of Staphylococcus.

For convenience the name 'penicillin' was used in place of the rather cumbersome phrase 'mould-broth filtrate'. Fleming showed that penicillin had a specific action on certain bacteria (Staphylococcus, Streptococcus, Pneumococcus, Gonococcus and the diphtheria bacillus), but that others ( $B$. coli and $B$. influenzos) were not affected. The first practical application of penicillin was the isolation of the insensitive Pfeiffer's bacillus, which in the respiratory tract is usually associated with organisms highly sensitive to penicillin. But Fleming also stated that penicillin had no poisonous effect and that "it may be an efficient antiseptic for application to, or injection with, areas infected with penicillin-sensitive microbes". In 1931, he prophesied that "it is quite likely that it, or a chemical of a similar nature, will be used in the treatment of septic wounds". In the following year Ristrick and his collaborators grew the Penicillium (which Thom identified as $P$. notatum) in a synthetic medium consisting solely of glucose and inorganic salts, and defined the optimum conditions of growth. They acidified the medium slightly, extracted with ether, and on removal of the ether obtained the anti-bacterial substance in a crude form and to it restricted the name penicillin. It was found to be extremely labile. A very definite step had been taken* and sulphonamides were not yet discovered. It remained for $\mathrm{H}$. W. Florey and his collaborators to reveal the outstanding therapeutic properties of penicillin. Florey worked first with lysozyme, another of Fleming's discoveries, and in the search for other anti-bacterial substances produced by

" "Another point which shows what practical results may be expected from such research is that penicillin, a metabolism produc of Penicillium notatum is non-irritant and non-toxic, but has a strong though differential antibacterial power." Presidential Address to Section $K$ of the British Association, Ann. Rept. Brit. Assoc., 1936, p. 215 . micro-organisms, E. Chain and Florey turned their attention to penicillin. A culture of Fleming's fungus was obtained and the penicillin was extracted with amyl acetate. Shaking out the amyl acetate with a buffer solution and evaporating the buffer solution gave a substance which was at first thought to be pure penicillin because it proved to be so active. The results of the clinical trials published in 1940 showed that it possesses unique therapeutic properties which, moreover, because of its non-toxicity, make it of outstanding value in the treatment of war wounds. But the penicillin used in these chemical experiments was only about 1 per cent pure. Several workers here and in the U.S.A. are engaged on research in purifying penicillin; a crystalline sodium salt has been obtained which is substantially pure and is a hundred times more active than the first extractions. It is capable of inhibiting the growth of certain bacteria at a dilution of about $1: 50,000,000$. Penicillin is a complex acid of which the exaet structure is not yet known.

Until recently, all the Penicillin notatum used, both in the laboratory and in large-scale manufacture, was from Fleming's original isolation. It was indeed a strange chance which led to the contamination of a laboratory culture by an apparently uncommon mould (originally described from decaying hyssop in Norway); and that the laboratory should be that of one who was curious in antibiotic phenomena and who, convinced of the value of his discovery, kept not only the original plate but also maintained the mould in culture. Further, it was fortunate that the original Oxford isolation of crude penicillin contained little if any toxic substances, with the result that Florey and the Oxford team were so soon able to announce almost undreamed-of achievements. This general freedom from association with harmful products incidentally has also characterized 'home-grown cultures' of penicilhn.

Penicillin is the most active bacteriostatic substance so far known; but the difficulty of obtaining sufficient quantities and its unstable quality have led to the search for similar mould products, and has also stimulated general research. There are many such products known, but few are sufficiently nontoxic for use. Flavicin from Aspergillus flavus and gigantic acid from $A$. giganteus are most similar to penicillin in their chemical and biological properties.

Raistrick and his colleagues have tested many of the compounds they had isolated and all new substances which were obtained. The product of the fermentation of Penicillium patulum (originally isolated from sheep dung in France) was considered promising and was sent to W. E. Gye, who is studying the effects of various substances on cancer cells. As he was suffering from a cold, he used it on himself with most satisfactory results. Extended trials show that it is able to cure a promising number of cases of one form of the 'common cold'. It has since been shown that patulin is identical with clavacin and clavatin obtained from Aspergillus clavatus, and claviformin, from Penicillium claviforme and Aspergillus giganteus. It is not surprising that the same chemical substance should be formed by several fungi -indeed, this is what one would expect. What is of greater interest is that it is also produced by Penicillium expansum. Van Luijk in 1938, studying the diseases of grasses caused by species of Pythium, found a difference in plants grown in sterilized and non-sterilized soil. $\mathrm{He}$ isolated a number of fungi 
from the soil and from the air and tested their influence on the growth of Pythium. He found that Penicillium expansum was the most markedly antibiotic, and adopting Fleming's procedure, obtained sterilized filtrates: these inhibited the growth of Pythium debaryanum at dilutions of $1: 1,280$. $\mathrm{He}$ did not isolate the antifungal substance, which Anslow, Raistrick and G. Smith (1943) have shown to be patulin. When the fungus was added to garden soil infected with Pythium, seedlings remained healthy instead of damping off.

Here we seem to have a linking up of different lines of research in such a way that we may expect considerable progress. The recognition of the chemical constitution of a substance produced by a common soil fungus which suppresses the growth of a plant pathogen suggests that greater precision may soon be given to many of the older observations on fungal antagonism of various kinds. Incidentally, it may also have some bearing on the question of natural compost versus chemical fertilizers. There is a difficulty in establishing the growth of antagonistic organisms in the soil; this can be done only by modifying the conditions, and an obvious way to do this is to add manure or compost which favour fungal growth. That the matter is not quite so simple as it appears at first sight, however, may be judged from the fact that Barnum in 1924 showed that the filtrate of cultures of Penicillium expansum caused wilting in certain herbaceous plants placed in it.

No more than mention can be made of the production by fungi of fats, ethyl alcohol, lactic acid, vitamins, and enzymes, or of the immense fermentation industries of the Orient.

\section{PLASTICS AND ELECTRICAL TECHNOLOGY}

$P$ LASTICS and electrical technology are close allies on the industrial front, with many points of contact, and in recent years meetings have been arranged at which members of the two professions can exchange views and comments on recent de. velopments of common interest. The latest meeting of this kind, arranged by the Plastics Group of the Society of Chemical Industry, was held at the Institution of Electrical Engineers on April 14, when the topics selected. were the electrical properties of the newer thermoplastics, radio-frequency heating, and 'tracking'.

In opening the discussion, Mr. H. A. Nancarrow pointed out that in the pure hydrocarbon thermoplastics, poly-ethylene, poly-isobutylene and polystyrene, we have arrived at the almost perfect dielectric, in the sense that their power factors are almost vanishingly small, over the entire range of frequency and temperature encountered in electrical practice. In these materials we have the excellent qualities of pure paraffin wax associated with a wide range of mechanical qualities from great flexibility to brittleness. The power factors of the pure materials are, generally speaking, of the order of $0 \cdot 0003$. Much higher values are sometimes quoted, but they are usually due to impurities; either plasticizers added to facilitate extrusion or moulding of the material, or oxidation products, produced when the material has been overheated in air. These materials have made possible many developments in electrical communica- tion at the highest frequencies, where even the smallest power factor, or power loss per cycle, may be very significant. At lower frequencies where higher power factors can be tolerated, thermoplastics like poly-vinyl chloride, which is doing valuable service as a rubber substitute in power cables, and polymethyl methacrylate, well known as 'Perspex', are being widely used. The power factors of these materials are of great scientific interest. They show the characteristic of all polar materials-a high maximum value at a particular frequency or periodic time corresponding with the relaxation time of the molecule. The work of Fuoss and other workers in America on the effect of plasticizers on this molecular relaxation was reviewed, but the discussion showed that though the spade work is progressing well, it has not yet reached the stage where important generalizations are possible.

In opening the discussion on the second topic, Dr. L. Hartshorm remarked that it has recently received a great deal of publicity under such very questionable terms as 'radiotronic' heating and 'heatronic' processes. These newly coined terms seem to be entirely unnecessary. The term 'radio-frequency heating' is satisfactory, but it includes eddy-current heating of metals at radio-frequencies, as well as that of plastics and other insulating materials by the process under discussion, which Dr. Hartshorn suggested should be called 'dielectric heating'. The meeting appeared to be prepared to accept the suggestion. The basic facts have long been known. Any solid or liquid insulating material placed near a conductor which is maintained at a high alternating voltage of high frequency becomes more or less hot. The heat is generated throughout the whole mass of the material, the rate of conversion of electrical energy into heat in any element of volume being proportional to the square of the electric field-strength in that element. The basic experimental facts were forced on the attention of radio engineers in the earliest days of high-power wireless transmitters : insulating supports frequently became so hot as to catch fire, and much research has been needed to discover materials like the pure hydrocarbons discussed by Mr. Nancarrow in which the development of heat is as small as possible, and those which will resist better the action of the heat that is developed. The new ceramic materials are of this class.

The idea of utilizing this generation of heat for industrial purposes seems to have originated in various quarters about fifteen years ago, though it has only quite recently been put into practice on any extensive scale. American patent literature from 1930 onwards describes various schemes for using dielectric heating for sterilizing milk and other foods, killing pests in plant bulbs, drying artificial sponges and tobacco, cementing plywood and safety glass, and leather soles on to shoes, and so on. At first sight it seems curious that the method is still a novelty in industry; no doubt economic factors as well as the technical difficulties have played their part here.

The importance of the process lies in the fact that it makes possible the rapid and uniform heating of thermal non-conductors of any thickness. In a large: American plant stacks of plywood $1 \mathrm{ft}$. thick are said to be heated through a temperature range of $160^{\circ} \mathrm{F}$. in five minutes, this rise of temperature being required for the setting of the urea-formaldehyde glues employed in the making of the plywood. The method has also proved valuable in the plastics 